\section{Subtle Interactions Guide the Course of Research To the Editor,}

As I was browsing through some back issues of MRS Bulletin, I came across your excellent article on Professor Frank Nabarro (Profiles \& PersPeCtives, MRS Bulletin, Vol. 29 No. 11, November 2004 , p. 875). While reading the article, I remembered an interesting experience that I wish to share with you.

Back in 1988, I was in the process of writing my PhD thesis (Queen's University, Kingston, Canada), and Professor Nabarro was spending a couple of weeks in our department. Professor Shigeo Saimoto suggested that I meet with Professor Nabarro. We spent a few hours in the rather large room I had at my disposal, and I spent most of that time at the blackboard explaining my findings. The topic was on three-dimensional island growth of semiconductor thin films with the zinc-blende structure grown by molecular-beam epitaxy. I was explaining a possible mechanism of the spontaneous formation of twins and the reasons for their anisotropic distribution. Their visibility in cross-sectional transmission electron microscope images depended on the $\{011\}$ planes used for sample preparation. I was suggesting - based on free energy of formation, taking into account surface and interfacial energies - that during the very early stages of thin-film formation from the vapor phase, two preferred orientations of islands could form more easily than any randomly oriented island. Namely, islands could form that had an epitaxial relationship with the single-crystal substrate, and "twinned" islands also had an equal probability to form as "epitaxial" islands.

Professor Nabarro did not speak much, but rather he concentrated very attentively on what this young chap was postulating. He appeared to be listening and absorbing everything I was saying, and I could feel that he was analyzing all of the information to make sure that laws of physics were not being broken. After some silent moments, he said to me, "Young man, you have something new." These words meant a lot to me and energized me to finish up the thesis and publish the work. Professor Nabarro seemed to invite new ways of thinking without any preconceived notions, and as a $\mathrm{PhD}$ student coming to the end of a long journey, I felt honored to be able to meet and discuss new ideas with surely one of the legendary figures of materials science.

SUDHI SANT

President, Twin Technologies Inc. Garden Grove, Calif.

\section{Send in Your Stories}

Many subtle (and not so subtle) interactions among scientists guide or change the course of research. MRS Bulletin is interested in hearing about those important moments. Please send us your stories. Send Letters to the Editor to Elizabeth L. Fleischer, Editor, at bulletin@mrs.org, or to MRS Bulletin, Materials Research Society, 506 Keystone Drive, Warrendale, PA 150867573, USA; fax 724-779-8313.

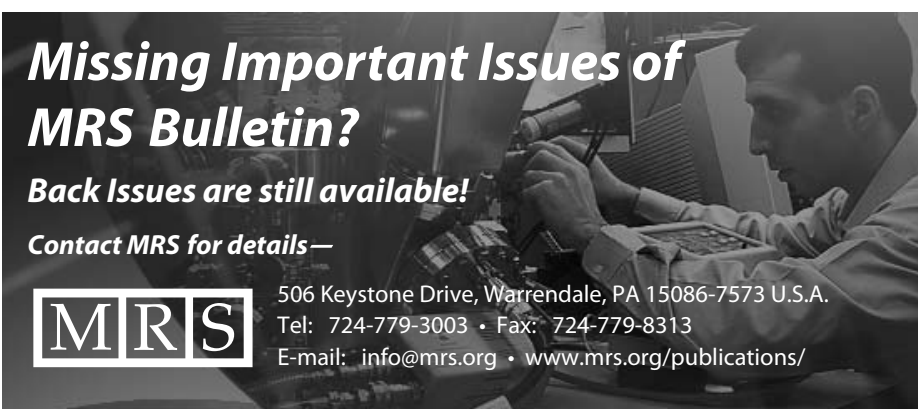

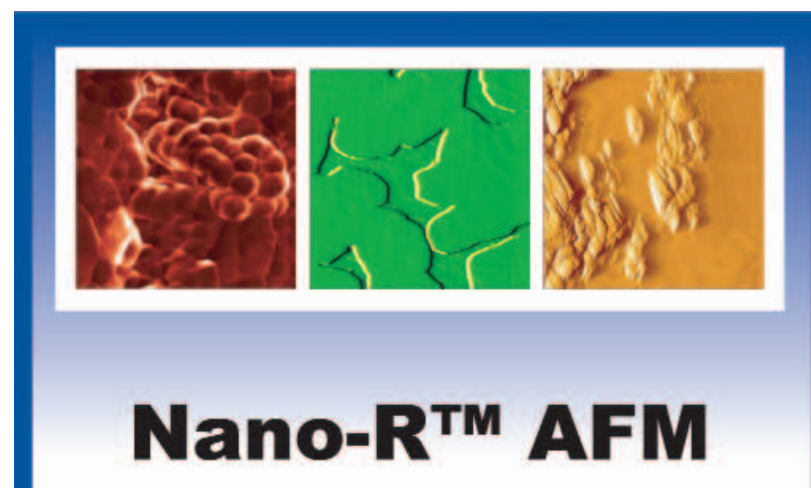

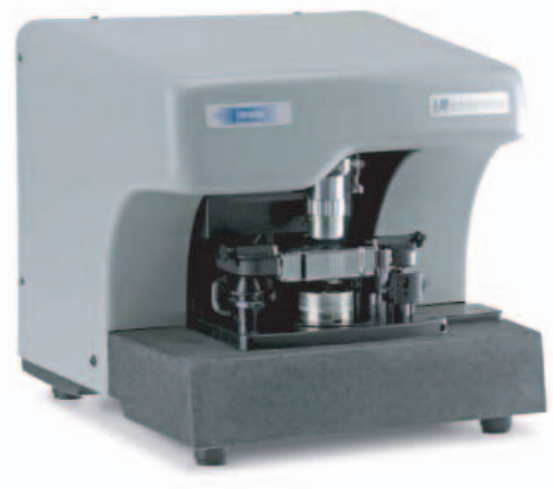

- High Performance

- Easy to Use

- Versatile

Nano- $R^{\mathrm{TM}}$ is available with a traditional light lever scanner and the advanced Crystal Scanner ${ }^{\mathrm{TM}}$.

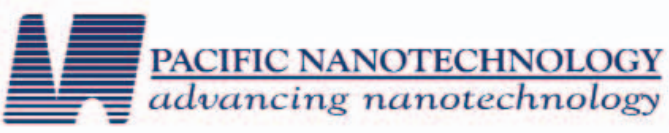

3350 Scott Blvd. \#29

Santa Clara, CA 95054

408-982-9492

www.pacificnanotech.com

www.probestore.com
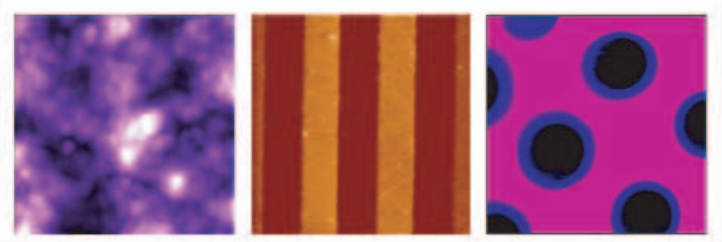

For more information, see http://advertisers.mrs.org 